\title{
Evaluation of Fluoroscopic Caudal Epidural Steroid Injections
}

To the Editor:

We read with interest the retrospective review by Southern et al (1) entitled Are Fluoroscopic Caudal Epidural Steroid Injections Effective for Managing Chronic Low Back Pain? However, we were disappointed at multiple aspects of the study which are enumerated below.

1. Southern et al (1) stated that to date, no study has specifically investigated the efficacy of fluoroscopic caudal epidural steroid injections as a treatment for patients with chronic lumbar discogenic back pain.

In contrast to this statement by Southern et al (1), Manchikanti et al (2-4) evaluated the role of caudal epidural injections in chronic low back pain in two prospective and one retrospective evaluation. Particularly in one study (3), they evaluated the role of caudal epidural injections in discogram positive and negative chronic low back pain, utilizing the International Association for the Study of Pain (IASP) criteria (5). Both the studies were performed in patients without radicular pain. Thus, they would be considered as chronic low back pain. It is quite possible that these patients may have had somatic lower extremity pain, however, not radicular pain. Further, all the patients were excluded for low back pain of facet joint origin with controlled comparative local anesthetic blocks prior to including them in the study for effectiveness of caudal epidural injections. This study showed that patients equally responded with fluoroscopically directed caudal epidural steroid injections in patients with or without positive concordant discogenic pain. Manchikanti et al (4) also retrospectively evaluated fluoroscopically directed caudal epidural injections and compared them with interlaminar and transforaminal epidural injections, the results of which have been quoted by Southern et al (1).

2. One of the inclusion criteria was "predominantly axial low back pain of more than 3 months' duration."
However, the authors have not defined and described the axial low back pain appropriately. Axial low back pain is considered as midline low back pain (does not include paravertebral low back pain), which is extremely difficult to manage (diagnosis and management) (6). It appears that Southern et al (1) have included all the patients with chronic low back pain without radicular pain, but with disc abnormalities. This will translate into not only axial pain, but also the chronic low back pain in the paravertebral region and probably somatic leg pain, as their other criteria for inclusion included clinical presentation and magnetic resonance imaging findings consistent with central lumbar disc protrusion and/or degeneration of $\mathrm{L} 4 / 5$ or $\mathrm{L} 5 / \mathrm{S} 1$.

3. The authors have deemed that the caudal procedures failed if the patients underwent subsequent discography and/or surgery after their injection.

The authors have not described if they have evaluated any of these patients for facet joint pain. Lumbar facet joint pain is commonly seen in patients with chronic low back pain, in fact, even more than discogenic pain (7-14). Surprisingly, the authors have offered discography to all the patients if they failed to respond or responded on a short-term basis to caudal epidural steroid injection as the only intervention.

4. In the Methods section, the authors have described that all patients who qualified for the study were mailed a Roland-Morris Disability Questionnaire and a North American Spine Society (NASS) Patient Satisfaction Questionnaire. Obviously, one would believe that these tests were only performed after the caudal epidural injections were performed, as this was a retrospective evaluation and the questionnaires were mailed following the decision to include them in retrospective evaluation.
In contrast, Table 4 shows pre-injection Roland-Morris functional scores in successful and failed groups of patients.

5. It was also surprising that among 4,756 charts reviewed, only 98 patients met the inclusion criteria. This is in fairly sharp contrast to common interventional pain management practices, indicating that the practice may be more of general physiatry practice rather than interventional pain management practice. We wonder if this somehow influences the selection and outcomes based on differing practice variables.

6. Follow-up period was highly variable from 3 months to 61.2 months.

7. The authors also have failed to define what was considered as short-term or long-term relief. It is well known that epidural injections provide short-term relief in a significant number of patients while they fail to provide long-term relief based on the definition of short-term being considered as 3 months or less (15).

8. The authors also have considered that perceived target area of pain and inflammation in this set of patients is the ventral, central epidural space, consequently, a caudal injection providing non-specific ventral epidural flow would possibly be the best choice of epidural steroid injection in this population. The inflammation in the ventral and central epidural space is considered most suspect in patients with radicular pain. In patients without radicular pain, disc degeneration with or without disc herniation can cause low back pain, but also facet joints, SI joints, ligaments, muscles and tendons (16-20). Proposed etiologies of discogenic pain secondary to disc herniation include not only neural compression, but also vascular compromise, inflammation, biochemical and neuromechanisms, internal disc disruption, intraneural 
and epidural fibrosis, dural irritation, findings of this limited study imply that and inflammation and swelling of 1) repeated and or 2) high volume and or dorsal root ganglion. Thus, it is 3) caudal with catheter procedures in papivotal for the interventionalist to tients 4) with or without positive radicupinpoint an anatomical diagnosis. lar signs and symptoms and or 5) posiIt is often cited that a cause cannot tive MRI would fail to respond, when as be determined in $85 \%$ of patients a matter of fact, the literature would supwith low back pain or conversely, port positive outcomes.

that a diagnosis is possible in only some $15 \%$ of cases (15) based upon history, physical exam and common radiological data. Further, radiographic investigations, on which authors heavily depended, including magnetic resonance imaging (MRI), reveal only certain conditions with certainty, namely, neural compression with radicular pain. Thus, the role of precision diagnostic injections has developed in the modern era.

9. The authors also should realize that some studies have used high volumes up to $40 \mathrm{~mL}$ in the past to show the effectiveness. Authors demonstrate that a $10 \mathrm{~mL}$ injection failed to reach beyond the L5/S1 level in many patients. Thus, the lack of efficacy of $10 \mathrm{~mL}$ caudal epidural steroid injection in a specific select population who may also be suffering with facet joint pain should not be construed as evidence that caudal epidural steroids performed would meet with similar failure. Finally, long-term outcome with a single injection is quite unrealistic.

In summary, we believe that this manuscript fails to fairly evaluate effectiveness of fluoroscopic caudal epidural steroid injections in the management of chronic low back pain with proper respect to a solid knowledge base of past literature on the subject (15). Indeed the article does not agree with past well-accepted and peer-reviewed literature. Hence, the authors should emphasize the various shortcomings of this manuscript. In this manner, insurers will not deny access to care for patients who do need caudal epidural steroid injections, thus limiting access to care based on an isolated and limited study. It should also be clearly stated that the authors do not believe that the

\section{REFERENCES}

1. Southern D, Lutz GE, Cooper G et al. Are fluoroscopic caudal epidural steroid injections effective for managing chronic low back pain? Pain Physician 2003; 6: 167-172.

2. Manchikanti L, Pampati V, Rivera JJ et al. Caudal epidural injections with Sarapin steroids in chronic low back pain. Pain Physician 2001; 4:322-335.

3. Manchikanti L., Singh V, Rivera J et al. Effectiveness of caudal epidural injections in discogram positive and negative chronic low back pain. Pain Physician 2002; 5:18-29.

4. Manchikanti L, Pakanati RR, Pampati V. Comparison of three routes of epidural steroid injections in low back pain. Pain Digest 1999; 9:277-285.

5. Merskey H, Bogduk N (editors). Classification of chronic pain. In: Descriptions of Chronic Pain Syndromes and Definition of Pain Terms, Second Edition. Seattle: IASP Press, 1994, pp. 180-181.

6. Bogduk N (ed). Low back pain. Clinical Anatomy of the Lumbar Spine and Sacrum. Second Edition. Churchill Livingstone, New York, 1997, pp 187-214.

7. Schwarzer AC, Aprill CN, Derby $R$ et al. Clinical features of patients with pain stemming from the lumbar zygapophysial joints. Is the lumbar facet syndrome a clinical entity? Spine 1994; 19:1132-1137.

8. Schwarzer AC, Wang SC, Bogduk N et al. Prevalence and clinical features of lumbar zygapophysial joint pain: A study in an Australian population with chronic low back pain. Am Rheum Dis 1995; 54:100106. Evaluation of the relative contributions of various structures in chronic low back pain. Pain Physician 2001; 4:308-316.

10. Manchikanti L, Singh V, Pampati V et al. Evaluation of the relative contributions of various structures in chronic low back pain. Pain Physician 2001; 4:308-316.

11. Manchikanti L, Pampati V, Fellows B et al. Characteristics of chronic low back pain in patients in an interventional pain management setting: A prospective evaluation. Pain Physician 2001; 4:131142.
9. Manchikanti L, Singh V, Pampati V et al.
12. Manchikanti L, Bakhit CE, Pakanati RR, Fellows B. Fluoroscopy is medically necessary for the performance of epidural steroids. Anesth Analg 1999; 89:13301331.

13. Manchikanti L, Pakanati RR, Pampati V. Comparison of three routes of epidural steroid injections in low back pain. Pain Digest 1999; 9:277-285.

14. Manchikanti L, Singh V, Pampati V et al. Is there correlation of facet joint pain in lumbar and cervical spine? An evaluation of prevalence in combined chronic low back and neck pain. Pain Physician 2002; 5:365-371.

15. Manchikanti L, Staats $P$, Singh $V$ et al. Evidence-based practice guidelines for interventional techniques in the management of chronic spinal pain. Pain Physician 2003; 6:3-80.

16. Wheeler AH, Murrey DB. Chronic lumbar spine and radicular pain: pathophysiology and treatment. Curr Pain Headache Rep 2002; 6:97-105.

17. Buckwalter JA. Aging and degeneration of the human intervertebral disc. Spine 1995; 20:1307-1314.

18. Mixter WJ, Ayers JB. Herniation or rupture of the intervertebral disc into the spinal canal. N Engl J Med 1935; 213:385-395.

19. McCarron RF, Wimpee MW, Hudkins PG et al. The inflammatory effects of nucleus pulposus: A possible element in the pathogenesis of low back pain. Spine 1987; 12:760-764.

20. Weinstein JN. The role of neurogenic and non-neurogenic mediators as they relate to pain and the development of osteoarthritis. A clinical review. Spine 1992; 10:S356-S361.

\section{Joseph Jasper, MD}

Medical Director

Advanced Pain Medicine Physicians 1628 South Mildred Street, Suite \#105

Tacoma, WA 98465

Email: apmedicine@qwest.net

Vijay Singh, MD

Medical Director

Pain Diagnostics Associates

1601 Roosevelt Road

Niagara, Wisconsin-54151

E-mail: vijsin@netscap.net

Hans C. Hansen, MD

Medical Director

The Pain Relief Centers, PA

3451 Greystone Place SW

Conover, North Carolina-28613

E-mail: hans@hippocrates.org 